\title{
STUDIES ON THE PIGMENTS OF MARINE ANIMALS -VI. CAROTENOIDS OF SOME TUNICATES-
}

AUTHOR(S):

Nishibori, Kokichi

CITATION:

Nishibori, Kokichi. STUDIES ON THE PIGMENTS OF MARINE ANIMALS -VI. CAROTENOIDS OF SOME TUNICATES-. PUBLICATIONS OF THE SETO MARINE BIOLOGICAL LABORATORY 1958, 7(1): 181-192

\section{ISSUE DATE:}

1958-12-20

URL:

http://hdl.handle.net/2433/174594

RIGHT: 


\title{
STUDIES ON THE PIGMENTS OF MARINE ANIMALS
}

\section{CAROTENOIDS OF SOME TUNICATES ${ }^{1}$}

\author{
KOKICHI NISHIBORI
}

Notre Dame Seishin College, Okayama

\section{With Plate XII, 3 Tables and 6 Text-figures}

Numerous, solitary and compound, tunicates show various colourations (red, orange, pink, etc.) owing to the presence of carotenoids. The distribution of carotenoids in tunicates has been studied by many investigators, and a comprehensive study was made by Goodwin (1952), as summarized in Table 1.

Table 1. Carotenoid distribution in tunicates (after Goodwin, 1952).

\begin{tabular}{|c|c|c|c|c|c|c|c|c|c|}
\hline Species & 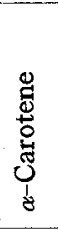 & 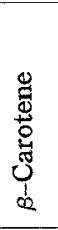 & 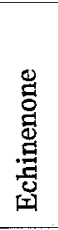 & 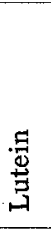 & 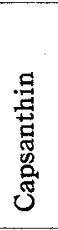 & 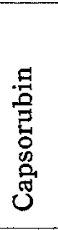 & 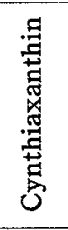 & 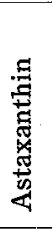 & 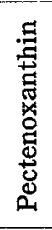 \\
\hline Botryllus schlosseri & & & & + & + & + & & & + \\
\hline Ciona intestinalis & & & & + & & & & & \\
\hline Clavellina lepadiformis & & + & & + & & & & & \\
\hline Corella parallelogramma & & $?$ & & + & & & & & \\
\hline Halocynthia papillosa & + & + & & & & & + & + & \\
\hline Dendrodoa grossularia & + & + & & & & & & + & \\
\hline Microcosmus sulcatus & $?$ & & $?$ & & & & & & \\
\hline Molgula occulta & & $?$ & & $?$ & & & & & \\
\hline Myxilla mammillaris & & $?$ & & $?$ & & & & & \\
\hline Styela rustica & & + & & $?$ & & & & & \\
\hline
\end{tabular}

1) Contributions from the Seto Marine Biological Laboratory, No. 322.

Publ. Seto Mar. Biol. Lab., VII (1), 1958. (Article 8) 
I have made some comparative studies of the carotenoids in four kinds of tunicates, three of which belong to the solitary form, Halocynthia roretzi (VON DRASCHE) (I) ${ }^{1}$, Pyura michaelseni (OKA) (II) and Styela plicata (LEsueur) (III) and one of the compound form, Amaroucium pliciferum (REDIKORzev) (IV).

The materials used for the experiment were collected at Hakodate, Hokkaido (I), Shirahama, Wakayama Prefecture (II, III) and Ushimado, Okayama Prefecture (II, IV).

\section{Experimental}

The general extraction and isolation method used in this report is shown in Table 2. Details in each species of the tunicates are described below:

Table 2. Extraction and isolation method for tunic carotenoids.

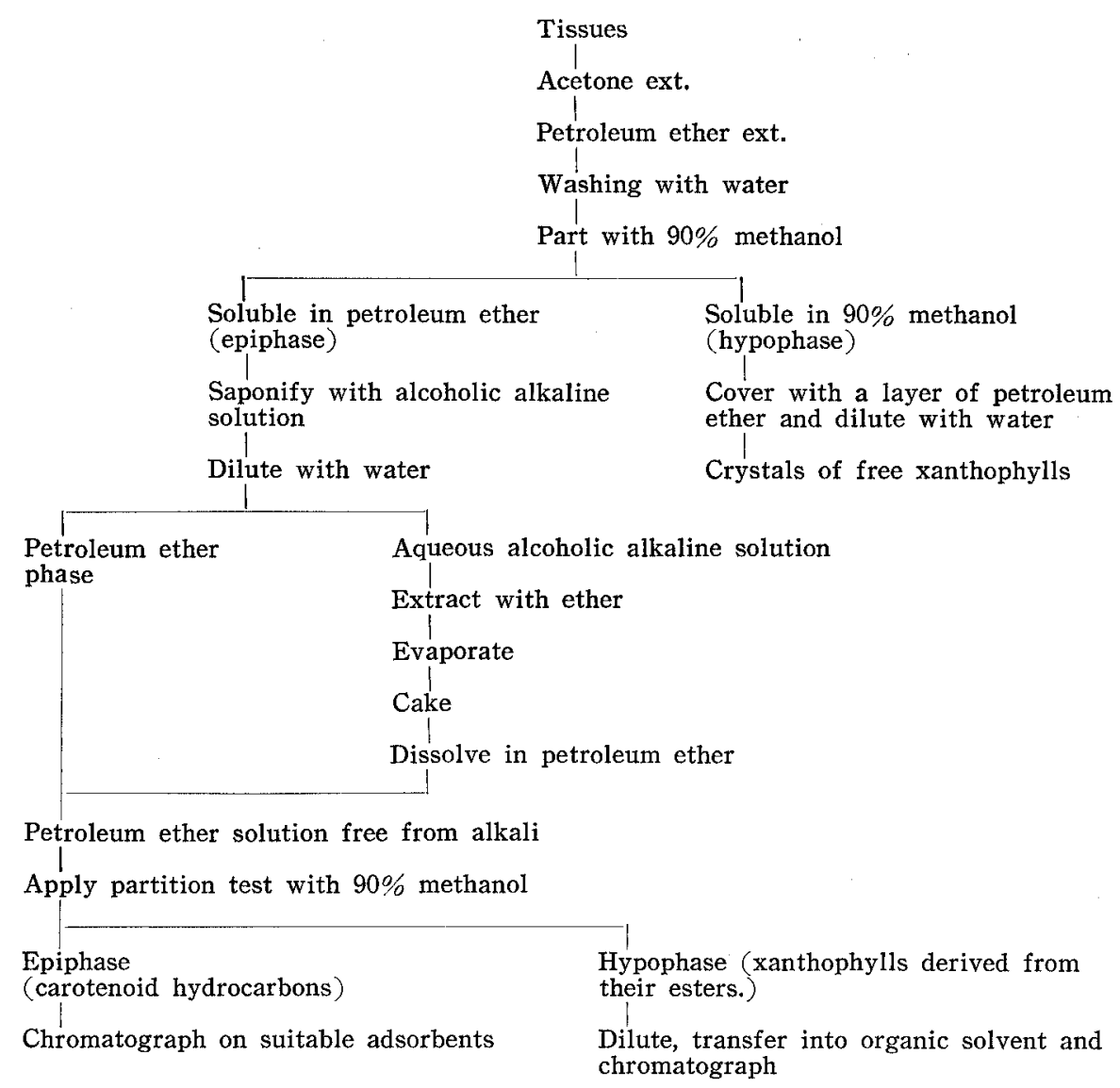

I. Halocynthia roretzi (Japanese name, Maboya)

An amount of 1350 gram of fresh tunics from 66 living specimens, collected at

1) The experimental studies on the sample (I) were carried out at Hokkaido University. 
Hakodate, Hokkaido, was used for the acetone extraction.

When the petroleum ether solution (bright deep red) containing the red pigments was washed with water in order to remove the acetone, crystalline orange-red materials were deposited on the surface boundary. The crystalline materials (A) were separated from the acetone-free petroleum ether solution (deep red) (B). The yield of (A) was about $560 \mathrm{mg}$.

Isolation of cynthiaxanthin: After washing with petroleum ether and recrystallization from the hot ethanol-water, the crystals (A) (m.p. $185 \sim 6^{\circ} \mathrm{C}$ ) were then chromatographed on calcium carbonate; an amount of $30 \mathrm{mg}$ of the crystals in 20 c.c. of ethereal solution was put into the column of calcium carbonate $(2.8 \mathrm{~cm} \times 25 \mathrm{~cm})$ and developed with ether.

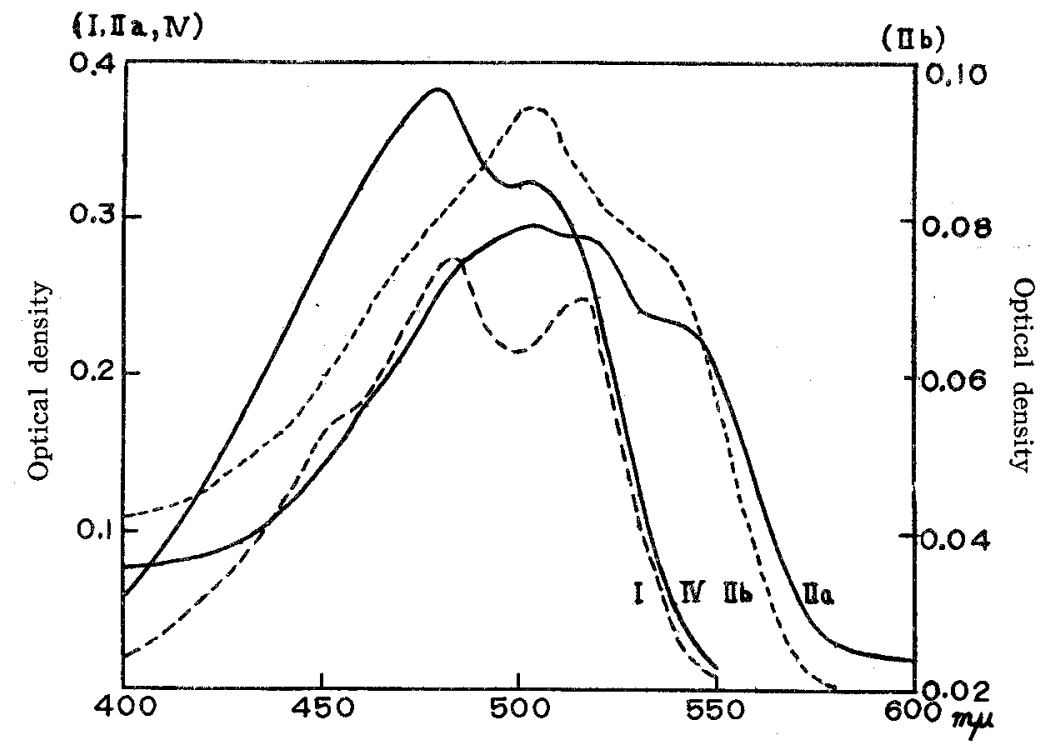

Fig. 1. Absorption spectra of cynthiaxanthin (I) from Halocynthia roretzi, a carotenoid (II a) and (II b) from the old (II a) and new (II b) specimens of Pyura michaelseni and a carotenoid (IV) from Amaroucium pliciferum, in carbon disulphide.

Two zones, the upper, brown red thin zone, and the lower, yellow orange main zone, were formed. The upper zone remained, when the main zone moved down through the column by the development with ether. An amount of $22 \mathrm{mg}$ of the refined crystals, m. p. 190 $2^{\circ}$, was recovered after recrystallization. (Plate XII, fig. 1 ).

Absorption spectrum and some other properties were summarized in Fig. 1, I and Table 3.

This pigment was soluble in methanol, ethanol, acetone, pyridine, ether, chloroform and benzene, but only slightly in petroleum ether. Blue colour was effected with CARR-PRICE reagent and with conc. $\mathrm{H}_{2} \mathrm{SO}_{4}$, but no colouration was given with conc. $\mathrm{HCl}$. 
Table 3. The principal carotenoids in the tunics of four tunicates.

\begin{tabular}{|c|c|c|c|c|c|}
\hline Species & \multicolumn{2}{|c|}{ Halocynthia roretzi } & $\begin{array}{c}\text { Pyura } \\
\text { michaelseni }\end{array}$ & Styela plicata & $\begin{array}{l}\text { Amaroucium } \\
\text { pliciferum }\end{array}$ \\
\hline $\begin{array}{l}\text { Colour of } \\
\text { tunic }\end{array}$ & \multicolumn{2}{|c|}{ dark red } & $\begin{array}{l}\text { reddish or pale- } \\
\text { brownish purple; } \\
\text { siphons deep red }\end{array}$ & $\begin{array}{c}\text { light dark } \\
\text { red }\end{array}$ & red \\
\hline Carotenoid & $\begin{array}{l}\text { Cynthia- } \\
\text { xanthin }\end{array}$ & Astacene & A xanthophyll & A xanthophyll & A xanthophyll \\
\hline $\begin{array}{c}\text { Crystalline } \\
\text { form }\end{array}$ & $\begin{array}{l}\text { orange long } \\
\text { prism }\end{array}$ & $\begin{array}{c}\text { black-violet } \\
\text { sickle shaped } \\
\text { needle } \\
\end{array}$ & $\begin{array}{c}\text { black-violet } \\
\text { sickle shaped } \\
\text { needle }\end{array}$ & & orange needle \\
\hline $\begin{array}{l}\text { Melting point } \\
\left({ }^{\circ} \mathrm{C}\right)\end{array}$ & $190 \sim 2$ & $223 \sim 5$ & $194 \sim 6$ & & 166 \\
\hline \multirow{2}{*}{$\begin{array}{l}\text { Absorp. max. } \\
(\mathbf{m} \mu)\end{array}$} & $\begin{array}{l}451,483,517 . \\
\mathrm{CS}_{2}\end{array}$ & & $\begin{array}{l}500 \sim 506, \sim 540 . \\
\mathrm{CS}_{2}\end{array}$ & & $479,503 . \mathrm{CS}_{2}$ \\
\hline & $\begin{array}{l}420 \sim 5,450, \\
480 . \text { P.E. }\end{array}$ & $\begin{array}{l}\text {-500. } \\
\text { pyridine }\end{array}$ & $\begin{array}{c}488 \sim 494, \sim 514 . \\
\text { pyridine }\end{array}$ & $\begin{array}{l}(\sim 410), \sim 435 \\
460, \sim 490 \\
\mathrm{CHCl}_{3}\end{array}$ & \\
\hline Partition test & hypophasic & hypophasic & hypophasic & hypophasic & hypophasic \\
\hline
\end{tabular}

These properties indicate that this pigment is undoubtedly identical with cynthiaxanthin.

Isolation of astacene: Fraction (B) was divided into epiphase and hypophase by shaking it with $90 \%$ methanol. Most of the red pigment in (B) was changed into the hypophase (deep red colour), while the epiphase gave only orange yellow. When the methanol solution containing hypophasic pigments was covered with a layer of petroleum ether and diluted with water, then the violet red crystals were doposited at the boundary of the two layers. The yield was about $130 \mathrm{mg}$. The crystals were washed with petroleum ether, then dissolved in a small amount of boiling ethanol and the insoluble violet-black crystals were separated from the mother

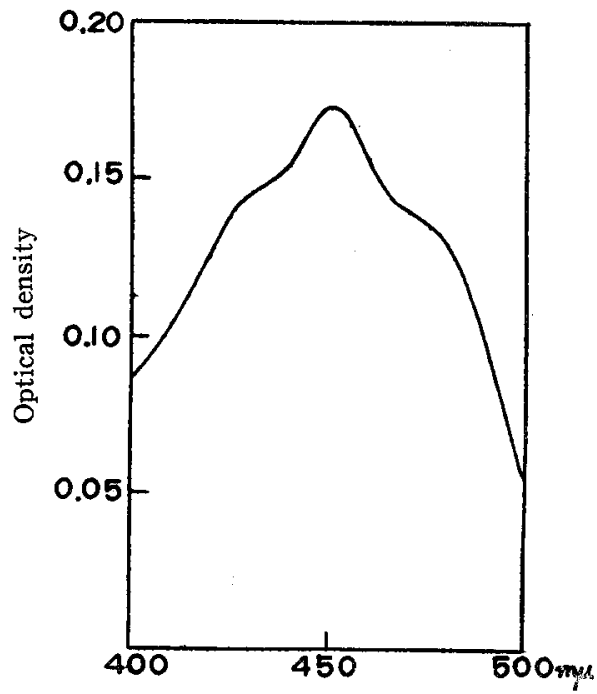

Fig. 2. Absorption spectrum of whole epiphasic carotenoid in Halocynthia roretzi, in petroleum ether. solution containing some more cynthiaxan-

thin. The crystals were washed with petroleum ether and methanol repeatedly and crystallized from pyridine-water. The melting point was $204^{\circ} \mathrm{C}$ and the yield was $26 \mathrm{mg}$. Then the crystals were dissolved in ethanolic potassium hydroxide, diluted with a small amount of water, and acidified with $50 \%$ acetic acid after the addition of a layer of petroleum ether. After that, the black violet crystals precipitated at the boundary of two layers, and these were recrystallized from pyridine-water as sickleshaped needles (m. p. $223 \sim 5^{\circ} \mathrm{C}$ ) after washing with hot water and petroleum ether. 
The absorption maximum showed at about $500 \mathrm{~m} \mu$ in pyridine. It was soluble in chloroform and pyridine but sparingly in petroleum ether and methanol. CARR-PRICE reaction $(+)$ violet-blue, conc. $\mathrm{H}_{2} \mathrm{SO}_{4}$ reaction $(t)$ blue. The melting point of the crystal did not fall when the mixed examination was carried on with astacene (m. p. $227 \sim 8^{\circ} \mathrm{C}$, absorp. max. $500 \mathrm{~m} \mu$ in pyridine, isolated from a crustacean (Pandalus sp.).

Thus, this pigment is identical with astacene. It seems that the astacene was recovered from the free astaxanthin in the tunic.

Carotenoids in epiphase: The carotenoid contents of this fraction (carotenoid hydrocarbons and xanthophyll esters) were so poor that the crystalline pigments could not be isolated. The absorption maxima of whole epiphase showed at $\sim 430,450$, $\sim 480 \mathrm{~m} \mu$ in petroleum ether (light orange yellow in colour) (Fig. 2).

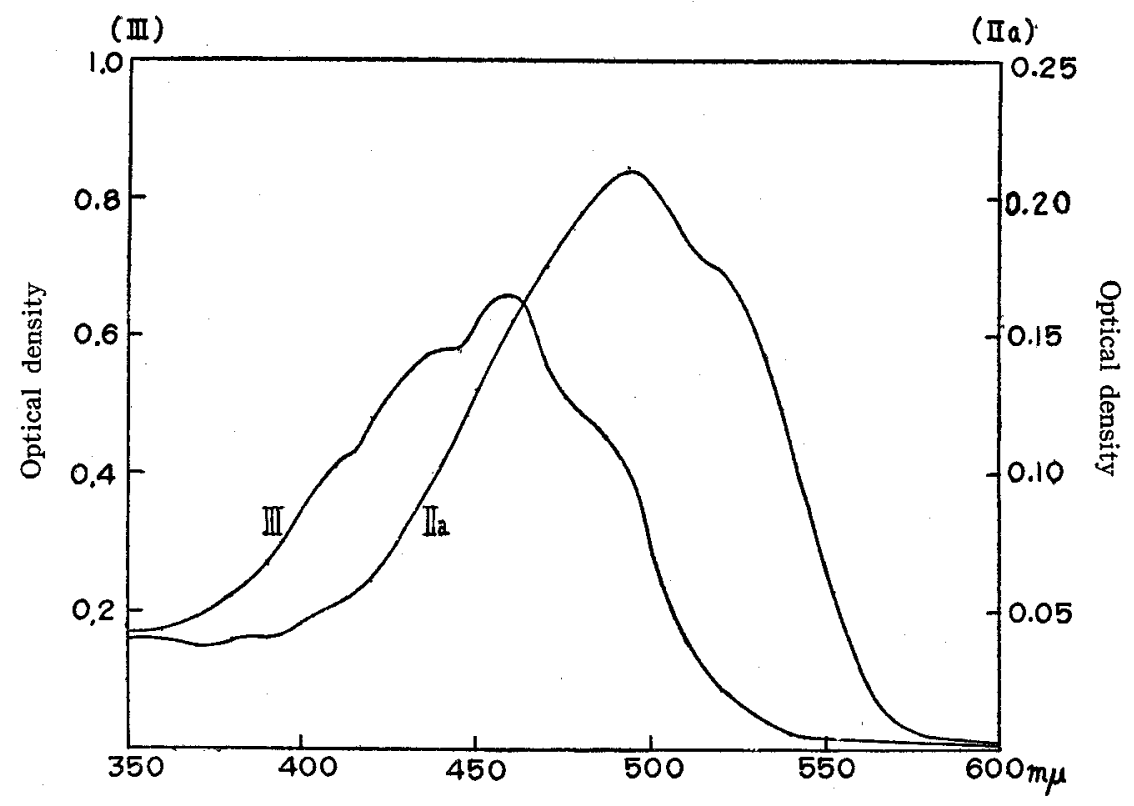

Fig. 3. Absorption spectra of a carotenoid from $P$. michaelseni (II a) and a carotenoid from S. plicata (III) in chloroform.

II. Pyura michaelseni (Japanese name, Mihaeruboya)

The pigments of this tunicate were examined on specimens collected at two different localities, one from Shirahama in Wakayama Pref. (specimens II a), and the other from Ushimado in the Seto Inland Sea (specimens II b).

Specimens (II a)

An amount of $690 \mathrm{~g}$ of the tunic from 120 specimens, which had been collected at Shirahama, Wakayama Pref. and stored for several months in the formalin solution, was used for materials.

Free xanthophyll fraction: Most of the red pigment in the acetone extract was 
changed into hypophase, from which the violet-red crude crystals were isolated. Then the pigment was washed with petroleum ether, and chromatographed on calcium carbonate from benzene solution and developed with the same solvent. Two zones resulted; the upper, a dirty red thin zone and the lower, a broad reddish pink main zone. The main adsorbed zone was cut off and the pigment was eluted with acetone, extracted with ether, and then the ether was evaporated in vacuo. The crystalline cake was dissolved in hot pyridine and drops of hot water were added. Then violetred needles, melted at $205 \sim 6^{\circ} \mathrm{C}$, were crystallized. For absorption spectra see Fig. 1 (II a, 505, $\sim 540 \mathrm{~m} \mu$ in $\mathrm{CS}_{2}$ ) and Fig. 3 (II a, 493, $\sim 520 \mathrm{~m} \mu$ in $\mathrm{CHCl}_{3}$ ). It was soluble in chloroform, carbon disulphide and pyridine but sparingly in petroleum ether and ether. CARR-PRICE reaction $(+)$ violet, conc. $\mathrm{H}_{2} \mathrm{SO}_{4}$ reaction $(t)$ blue, aqueous $\mathrm{HCl}$ reaction (-).

The yield was about $1 \mathrm{mg}$. The pigment showed hypophasic property (P.E./90\% $\mathrm{MeOH}$ ) and changed into an upper layer when a little water was added. When alkali was added, however, the pigment remained in the lower layer and was deposited interface. After that, the pigment changed into epiphase, when it was acidified by acetic acid. These properties indicate that this pigment is a ketonic carotenoid. Specimens (II b).

An amount of $380 \mathrm{~g}$ of the tunic from the 11 specimens collected at Maezima Island, Ushimado, and stored for twenty days in the formalin solution in a dark place, was used for materials.

Free Xanthophylls: The major pigments were found in the hypophasic 90\% methanol phase, from which the violet-black crystals were separated. The yield was about $4 \mathrm{mg}$. The crystals were dissolved in 15 c.c. of hot ethanol and added $2 \mathrm{~N}$ ethanolic potassium hydroxide and then allowed to stand for 3 hours. Then a layer of petroleum ether was added and diluted with water and then acidified with 50\% acetic acid. The black violet crystals, which were separated at the boundary of the two layers, were crystallized from pyridine-water (Plate XII, fig. 2). The yield was only about $1 \mathrm{mg}$. The properties of the crystal were as follows; m. p. $194 \sim 6^{\circ} \mathrm{C}$, absorption maxima, 500 506, $\sim 540 \mathrm{~m} \mu$ in carbon disulphide (Fig. 1, II b), 488 494, $\sim 514 \mathrm{~m} \mu$ in pyridine, easily soluble in carbon disulphide, chloroform, pyridine, sparingly soluble in ethanol, petroleum ether and ether, hypophasic property (P. E./90\% $\mathrm{MeOH}$ ), CARR-PRICE reaction $(+)$ violet, conc. $\mathrm{H}_{2} \mathrm{SO}_{4}$ reaction $(+)$ blue, conc. $\mathrm{HCl}$ reaction (-) and had a ketonic property.

Carotenoids in epiphase: This fraction was divided into two fractions; carotenoid hydrocarbons (A) and xanthophylls (B) derived from xanthophyll esters by saponification.

Both fractions were poor in pigments. Fraction (A) in the petroleum ether solution was chromatographed on alumina (Merck) and developed with petroleum ether containing acetone ( 1 and $5 \%$ ). Three zones, the upper red zone (i), the intermediate light yellow zone (ii) and the lower light pink orange zone (iii) were formed. The 
absorption spectra of the pigment which was eluted from zone (i) and (iii) were shown in the Fig. 4. The pigment of zone (i) was unable to elute completely with acetone containing acetic acid.

$$
\begin{aligned}
& \text { Zone ( i ) } \sim 390, \sim 460,483 \mathrm{~m} \mu \mathrm{CS}_{2} . \\
& \text { Zone (iii) } 390, \sim 450,478, \sim 510 \mathrm{~m} \mu \mathrm{CS}_{2} .
\end{aligned}
$$

Fraction (B) in ethereal solution was chromatographed on alumina and developed with petroleum ether containing acetone (10\%). Three zones, the upper dark-red zone (i), the intermediate red zone (ii) and the lower yellow zone (iii) were formed.

The absorption spectrum of the pigment which was eluted with acetone containing acetic acid from the main zone (i), showed the maximum at $\sim 490 \mathrm{~m} \mu$ in carbon disulphide (Fig. 4, I').

The results derived from the (fresh) specimens (II b), were used for the data of the pigments of the Pyura michaelseni.

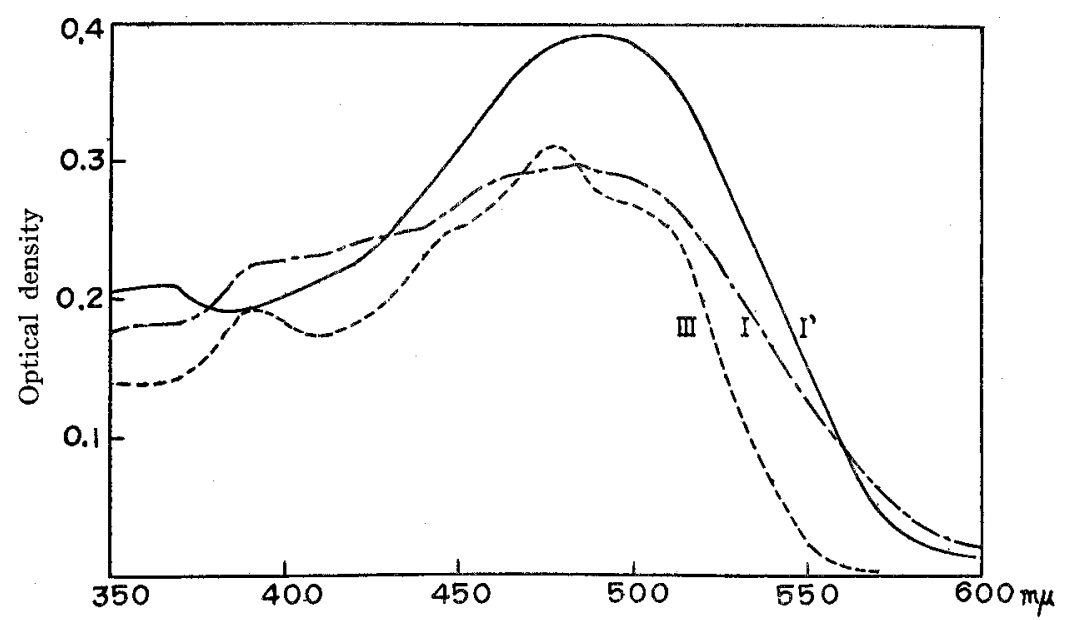

Fig. 4. Absorption spectra of the epiphasic carotenoids in $P$. michaelseni (specimens II b).

( I ), carotenoid hydrocarbon, zone i.

(III), carotenoid hydrocarbon, zone iii.

$\left(\mathrm{I}^{\prime}\right)$, a xanthophyll derived from xanthophyll ester.

\section{Styela plicata (Japanese name, Shiroboya)}

An amount of $160 \mathrm{~g}$ of the light dark red pigmented tunic from 40 specimens of Styela plicata collected at Shirahama, Wakayama Prefecture and stored for ten days in the formalin solution, was used for extraction. The acetone extract showed greenish dark orange in colour and the pigments were divided into two fractions; the brown green epiphase having light red fluorescence, and the dark orange hypophase by shaking with $90 \%$ methanol.

Free xanthophylls: Any attempt to crystallize the pigment from the hypophase which contains the most red pigment, failed. 
The amorphous red materials separated on the surface between the diluted hypophase and the additional petroleum ether layer, however, were washed with petroleum ether and dissolved in benzene and then, chromatographed on alumina (not adsorbed on $\mathrm{CaCO}_{3}$ or $\mathrm{ZnCO}_{3}$ ) and developed with benzene. Two zones, the upper, a dirty brown main zone and the lower, a dirty greenish brown zone which was just under the main zone, resulted. The lower zone moved down slightly but the upper zone did not move when the column was developed with petroleum ether containing acetone (5\%). The pigment of the upper zone was eluted with acetone and extracted with ether. Any attempt to crystallize failed. The absorption maxima of this pigment showed at $(\sim 410), \sim 435,460, \sim 490 \mathrm{~m} \mu$ in chloroform (Fig. 3, III). CARR-PRICE

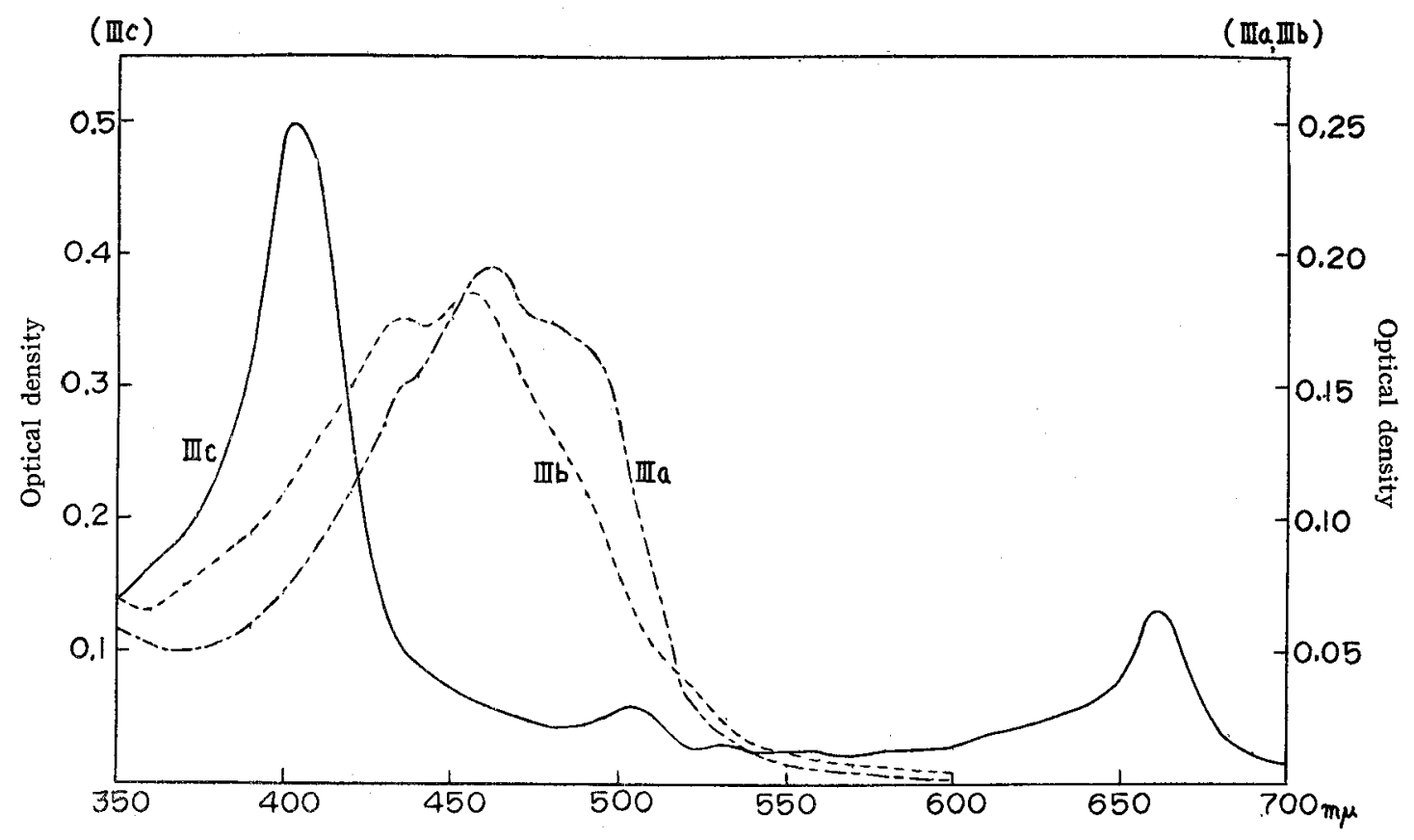

Fig. 5. Absorption spectra of the pigments in S. plicata.

(III a), carotenoid hydrocarbon, zone IV.

(III b), a xanthophyll derived from xanthophyll esters.

(III c), green pigment in alkaline equeous ethanol.

(III $a$ and $\mathrm{III} b$ in $\mathrm{CHCl}_{3}$ )

reaction ( + ) blue, conc. $\mathrm{H}_{2} \mathrm{SO}_{4}$ reaction $(+)$ blue, aqueous conc. $\mathrm{HCl}$ reaction $(-)$.

Carotenoids in epiphase: The epiphase was divided into three fractions; the yellow petroleum ether solution (A) containing carotenoid hydrocarbons, the yellow ethereal solution (B) containing xanthophylls derived from xanthophyll esters and the greenish aqueous alcoholic alkaline solution (C) after saponification. Fraction (A) was chromatographed on alumina and developed with petroleum ether. Four zones 
beginning at the top of the column resulted; the dark violet red (i), the orange red (ii), the reddish orange (iii) and the broad orange red main zone (iv). Zone (iv) was moved down slowly forming a thin zone when the column was developed with petroleum ether containing acetone (2\%). The pigment of (iv) was eluted with acetone and after evaporation of acetone in vacuo, the pigment was dissolved in chloroform and the absorption maxima were determined. The maxima showed at $\sim 435,462, \sim 490 \mathrm{~m} \mu$. (Fig. 5, III a). CARR-PRICE reaction ( $(+)$ blue.

Fraction (B) was chromatographed on alumina from benzene solution and developed with acetone-petroleum ether mixture $(1: 1)$. Two zones, the orange thin zone forming at the top of the column, and the lower light yellow broad zone, were formed. The pigment of the latter was washed out with acetone and dissolved in chloroform after the evaporation of acetone. The absorption maxima of the latter showed at 437, $456 \mathrm{~m} \mu$. (Fig. 5, III b). CARR-PRICE reaction ( + ) blue. Fraction (C) showed the absorption maxima at 402, 503, $660 \mathrm{~m} \mu$ (Fig. 5, III c). The highest maximum laying at $402 \mathrm{~m} \mu$ shows that the principal pigment of fraction (C) belongs to the porphyrin pigment.

\section{Amaroucium pliciferum (Japanese name, Manzyuboya)}

The whole bodies $(680 \mathrm{~g})$ of the 27 living specimens collected at Maezima Island, Ushimado, Okayama Prefecture, were treated with acetone.

Free xanthophyll fraction: Most of the red pigments were found in the hypophase (blood red), from which the major carotenoid was crystallized in the form of violet needles.

Then the crystals were chromatographed on alumina from ethereal solution and developed with ether containing acetone $(0.2 \%)$. Three zones, the uppermost, red orange zone (i), the intermediate, carmine red orange zone (ii), and the lower, bright orange main zone (iii) were formed.

The pigment of (iii) was eluted with acetone-ether mixture (1:1) and the crystalline materials (about $2.8 \mathrm{mg}$ ) were rechromatographed on zinc carbonate from benzene solution and developed with benzene and ether.

Then the single zone, which moved down slowly, was formed and the pigment was eluted with acetone and crystallized from the hot pyridine.

The properties of the crystal were as follows; orange needle (Plate XII, fig. 3), m. p. $166^{\circ} \mathrm{C}$, absorption maxima at $479,503 \mathrm{~m} \mu$ in carbon disulphide (Fig. 1, IV), CARR-PRICE reaction $(+)$ blue, conc. $\mathrm{H}_{2} \mathrm{SO}_{4}$ reaction $(+)$ blue, aqueous conc. $\mathrm{HCl}$ reaction (-). It was soluble in chloroform, benzene, carbon disulphide, pyridine, and sparingly soluble in petroleum ether. The pigment showed hypophasic property but showed epiphasic when it was treated with acetic acid anhydride and pyridine to form ester. After saponification of the ester, however, the pigment returned to hypophase. Thus, this pigment has more than one $\mathrm{OH}$ group.

Carotenoids in epiphase: Both fractions, the carotenoid hydrocarbons (A) and the esterified xanthophylls (B) were poor in pigment. 
The pigments of (A) in petroleum ether were chromatographed on alumina and developed with petroleum ether containing acetone (5\%). The light pink brown zone (absorp. max. 465, ( 510) $\mathrm{m} \mu$ in $\mathrm{CS}_{2}$ ) (Fig. 6, IV a) was formed and the yellow coloured filtrate showed the absorption maxima at $475, \sim 495 \mathrm{~m} \mu$ in carbon disulphide. (Fig. 6, IV b).

The pigments of (B) in ethereal solution were chromatographed on zinc carbonate and developed with ether. The pink brown zone (absorp. max. $465 \mathrm{~m} \mu$ in $\mathrm{CS}_{2}$ ) (Fig. 6, IV c) which moved down gradually, was formed and the bright yellow filtrate showed no selective visible light absorption (Fig. 6, IV d).

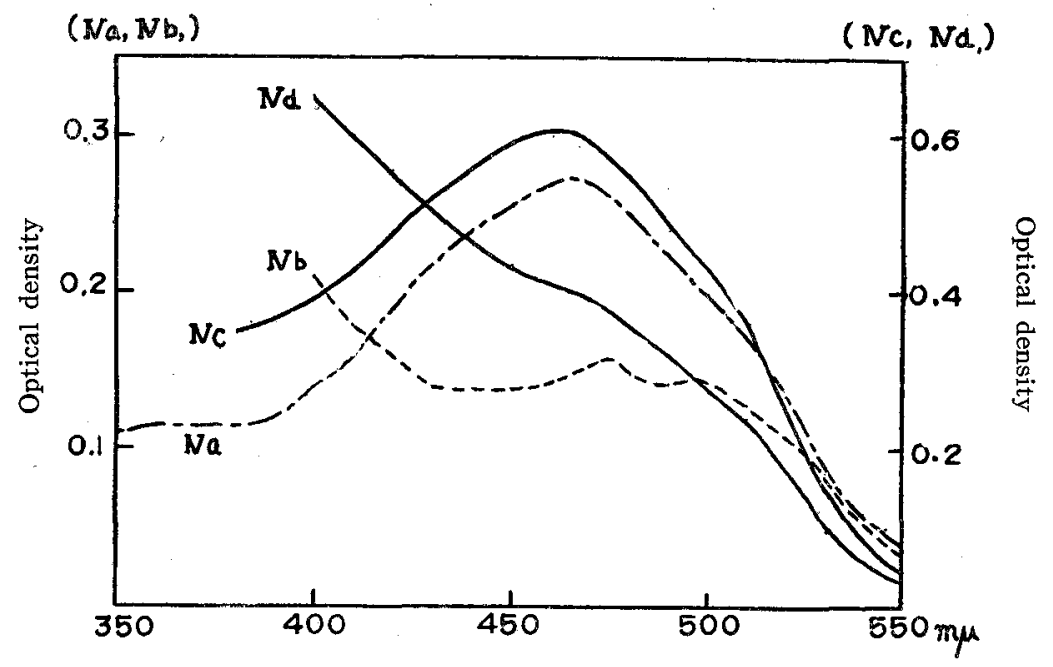

Fig. 6. Absorption spectra of the carotenoids in A. pliciferum.

(IV a) an adsorbed and (II b) non-adsorbed carotenoid hydrocarbon fraction, (IV c) an adsorbed and (IV d) non-adsorbed xanthophyll fraction derived from their esters, in carbon disulphide.

\section{Summary}

Some comparative studies of the pigments of four species of tunicates, Halocynthia roretzi (I), Pyura michaelseni (II), Styela plicata (III) and Amaroucium pliciferum (IV), have been carried out.

The major pigment of each species was a free xanthophyll (phytoxanthin), which was isolated in the crystalline form from the specimens of (I), (II) and (IV).

The principal carotenoid of four species was different each other (Table 3). From the dark red tunics of Halocynthia roretzi (I), astacene and a free xanthophyll which is recognized to cynthiaxanthin have been isolated as predominant carotenoid. Cynthiaxanthin is a unique xanthophyll which has been isolated from the dark red tunic of Halocynthia papillosa by LEDERER (1934), who recovered $1 \mathrm{mg}$ of the 
cynthiaxanthin accompanied with $4 \mathrm{mg}$ of astacene from fifteen specimens. KARRER and Solmssen (1935), however, could not detect cynthiaxanthin from the same species.

Astacene of (I) was recovered from the free astaxanthin occurring in the tunic.

The principal carotenoid in the reddish purple tunic of Pyura michaelseni (II) is a free xanthophyll which melted at $194 \sim 6^{\circ} \mathrm{C}$ and showed absorption maxima at $500 \sim 506, \sim 540 \mathrm{~m} \mu$ in carbon disulphide, $488 \sim 494, \sim 514$ in pyridine. It has a ketonic property.

The pigment of the light dark red tunic of Styela plicata (III) was extracted with acetone and the extract contained carotenoids and the pigment appeared to be porphyrin pigment. No crystalline pigment has been obtained from both fractions, but the absorption spectra of the principal carotenoid of the former, which refined chromatographically, showed the maxima at $(\sim 410), \sim 435,460, \sim 490 \mathrm{~m} \mu$ in chloroform, and the latter showed at 402,503, $660 \mathrm{~m} \mu$ in alkaline aqueous ethanol solution.

From the whole acetone extract of Amaroucium pliciferum, a brilliant red pigmented colony tunicate, a free xanthophyll having absorption maxima at $479,503 \mathrm{~m} \mu$ in carbon disulphide and melting at $166^{\circ} \mathrm{C}$, has been isolated.

Moreover, spectrophotometric examinations on the accompanying small amounts of carotenoid hydrocarbons and esterified xanthophylls in each species, were carried out.

\section{Acknowledgments}

The author wishes to express his deep gratitude to Professor Y. NAKAMura and Professor T. SaIto of Hokkaido University, for their encouragement and guidance. The author is also grateful to Dr. H. Utinomi, Dr. T. Tokioka, Mr. E. Harada and Mr. S. FuSE of Seto Marine Biological Laboratory of Kyoto University, for laboratory facilities during his stay for collecting tunicate samples and also for helpful biological suggestions.

\section{REFERENCES}

Goodwin, T. W. 1952. The Comparative Biochemistry of the Carotenoids, Chapman \& Hall Ltd., London.

KARRER, P. und SolmSSEN, U. 1935. Über des Vorkommen von Carotenoiden bei einigen Meerestieren. Helv. $18: 915-921$.

LEDERER, E. 1934. Sur les caroténoides de trois Ascidies (Halocynthia papillosa, Dendrodoa grossularia, Botryllus schlosseri). Compt. rend. Soc. Biol., 117 : 1086-8. 


\section{EXPLANATION OF PLATE XII}

Fig. 1. Cynthiaxanthin isolated from Halocynthia roretzi.

Fig. 2. Principal hypophasic carotenoid isolated from Pyura michaelseni (II b).

Fig. 3. Principal hypophasic carotenoid isolated from Amaroucium pliciferum. 


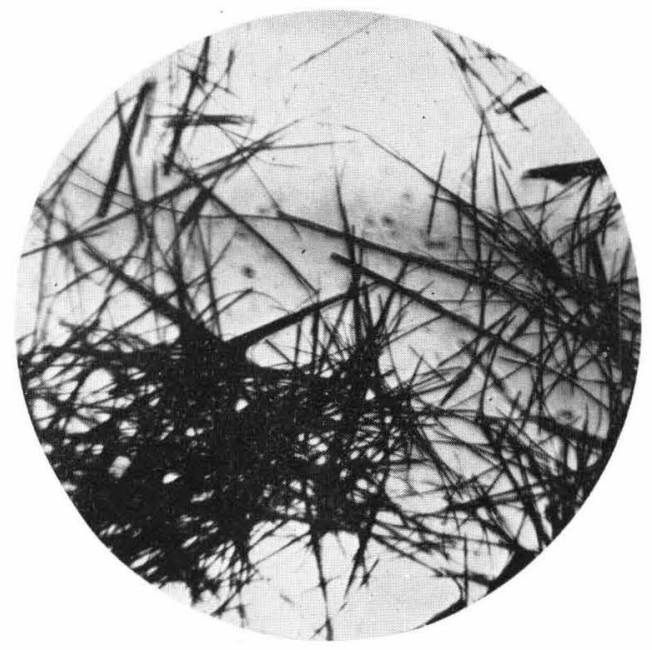

Fig. 1.

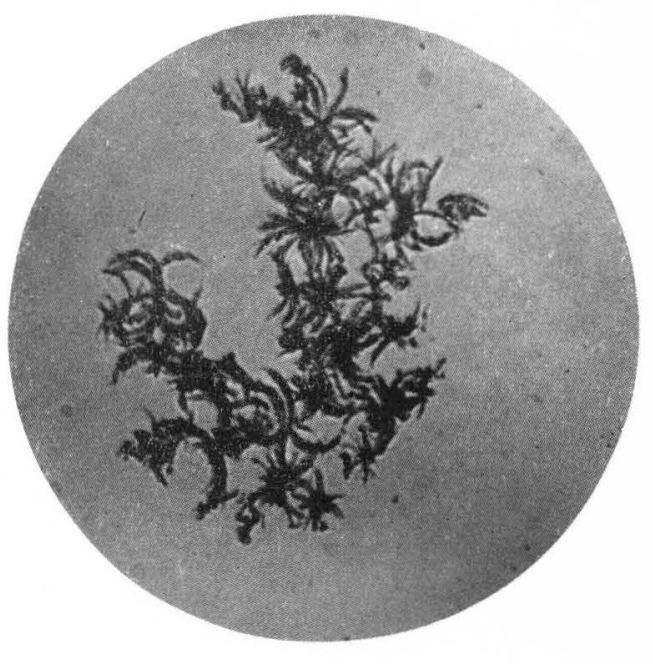

Fig. 2.

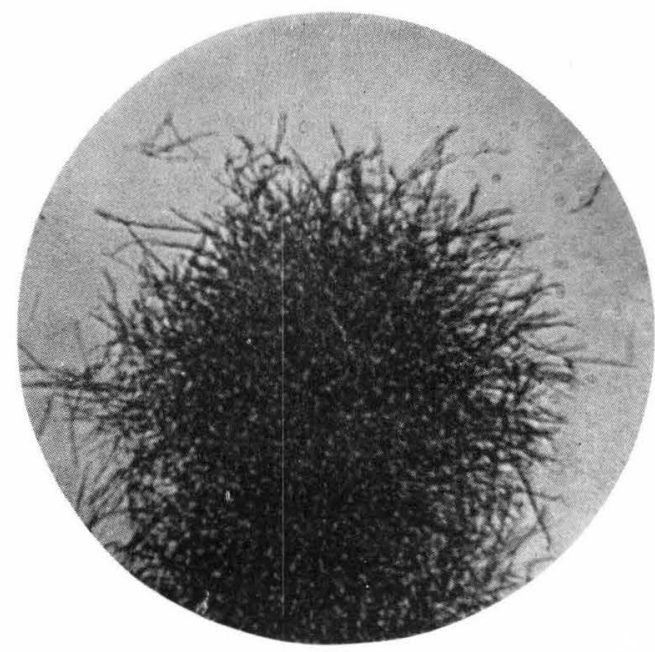

Fig. 3.

K. Nishibori: Studies on the Pigments of Marine Animals, Vi. 